\title{
How education gets in the way of learning
}

\author{
Professor Geoff Masters AO \\ Australian Council for Educational Research
}

https://doi.org/10.37517/978-1-74286-638-3_1

\begin{abstract}
Geoff Masters is the CEO and board member of the Australian Council for Educational Research. He has a PhD in measurement, evaluation and statistical analysis from the University of Chicago and has published widely in the fields of educational measurement, educational assessment and school improvement. Geoff has conducted a number of reviews for governments, including a review of examination procedures in the NSW Higher School Certificate; an investigation of options for the introduction of an Australian Certificate of Education; a national review of options for reporting and comparing school performances; reviews of strategies for improving literacy and numeracy learning in government schools in Queensland and the Northern Territory; and a review of senior secondary assessment and tertiary entrance procedures in Queensland. Most recently, he has reviewed the New South Wales school curriculum. Geoff's contributions to education have been recognised through the award of the Australian College of Educators' Medal and his appointment as an Officer of the Order of Australia.
\end{abstract}

\section{Abstract}

The formal structures and processes of school education - including the organisation of the school curriculum, processes for assessing student learning, methods of reporting performance, and the uses to which student results are put - are often inconsistent with what is now known about the best ways to promote human learning. Rather than being designed to maximise every student's learning, these structures and processes often reflect 20th century priorities, including the use of school education to sort and select students into different education and training destinations, and future careers. This sorting function of schooling is becoming increasingly irrelevant in knowledge economies that now look to their school systems to provide every student with high levels of knowledge, understanding and skill, including skills in critical and creative thinking, problem-solving, using new technologies, and working collaboratively with others. The challenge is to ensure that every student reaches the levels currently achieved by only some. However, the structures and processes of today's schools are often poorly designed to meet this challenge.

\section{The curriculum}

Consider, for example, the school curriculum. In its design, the current curriculum has much in common with an industrial-era assembly line. All students move along it at the same rate. Each year, the same curriculum is delivered to all students who are given the same amount of time to master it. They then move in lockstep to the next year's curriculum where the process is repeated. Students who have not mastered the content of the current year's curriculum and lack the prerequisites for the following year's curriculum move on regardless. Other students, who may not have required a full year to do this, are unable to advance to a more challenging curriculum until everybody moves in unison.

The consequence of this design is predictable. Students who lack the prerequisites for the next year's curriculum are also less likely to master that curriculum. As a result, they may be even less 
likely to master the curriculum in the year after that, and so on. Not surprisingly, many students fall increasingly far behind the longer they are in school and as year-level curricula become increasingly beyond their reach. By the middle years of school, many students have fallen so far behind that they begin to disengage. Some stop attending school entirely.

The curriculum designed in this way is an excellent sorting mechanism. It sorts out struggling students. Its effectiveness in doing this is clear from data on student achievement. Consider, for example, the data in Figure 1. These were collected by Professor Di Siemon and her colleagues who began by defining a number of levels of mathematical knowledge. These levels were not based on how old students were or what grade of school they were in; they were simply levels of increasing mathematical knowledge and understanding. Level 1 was the lowest, Level 8, the highest.

They then assessed Australia-wide samples of students in each of Years 5 to 9 to see which levels of mathematical knowledge students demonstrated. Figure 1 shows the results. At the top left, it can be seen that some Year 5 students were already at the highest level of mathematical knowledge Level 8. At the bottom right, some Year 9 students were still at the lowest level - Level 1. Siemon and her colleagues concluded that the spread within each year level was equivalent to about seven years of mathematics learning. Students toward the bottom right in Figure 1 no doubt have struggled with year-level mathematics curricula throughout their schooling. The Year 9 mathematics curriculum is now well beyond their reach and they have effectively been sorted out of the system.

Figure 1 Levels of mathematics knowledge - Australian students, Years 5-9

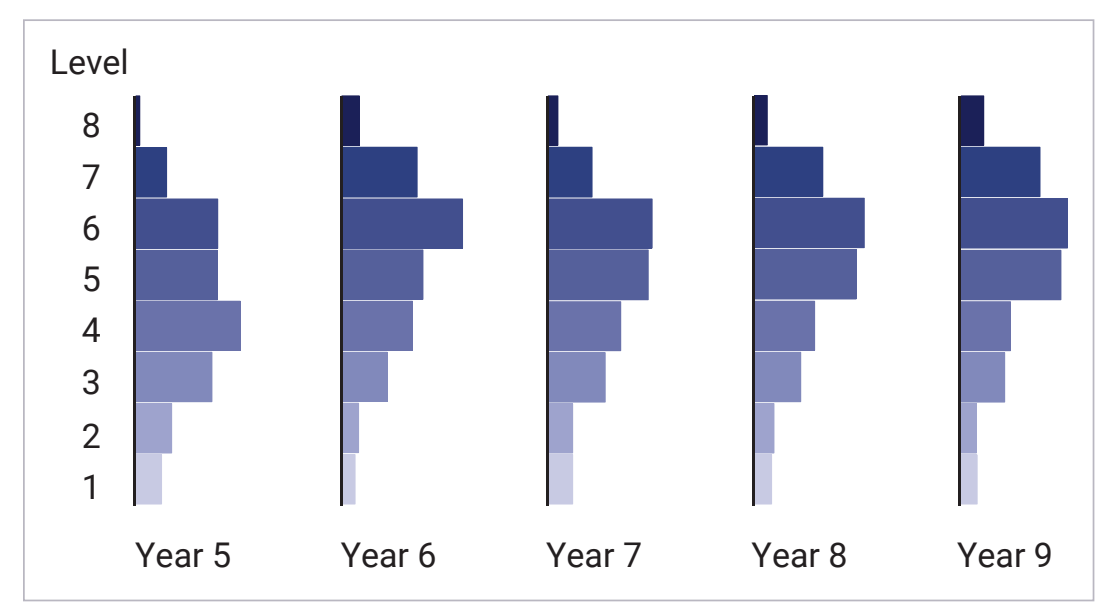

Note: The spread within each year level represents a range in students' mathematics achievement equivalent to seven years of schooling Source: Adapted from Siemon (2019, p. 13) ${ }^{1}$

In contrast to the current delivery of the curriculum, research shows that the way to maximise an individual's learning is to provide them with learning opportunities at an appropriate level of (stretch) challenge. People do not learn effectively when presented with material for which they lack prerequisite knowledge or skills or when given material well within their comfort zones. Learning opportunities need to be well targeted to individuals' present levels of attainment and readiness. For many students, this is precisely what the time-driven assembly-line curriculum, with its assumption that all students in the same year of school are more or less equally ready for the same learning, fails to do.

The school curriculum is also reminiscent of industrial processes in that it commonly breaks down subjects into component elements, usually referred to as 'outcomes' or 'objectives'. The intention is that each outcome will be taught and mastered. Many outcomes of this kind can result in a 'crowded'

Siemon, D. (2019). Knowing and building on what students know: The case of multiplicative thinking. In D. Siemon, T. Barkatsas, \& R. Seah (Eds.) Researching and using progressions (trajectories) in mathematics education. BRILL. https://doi.org/10.1163/9789004396449 
curriculum that teachers feel required to cover in the limited time available. Teachers also may be led to believe that they should assess every outcome individually. Under this thinking, the curriculum becomes a checklist of outcomes, all of which may appear equally important, with curriculum coverage taking precedence over depth of learning.

In contrast, research into learning underscores the importance of learners developing deep understandings of a relatively small number of essential concepts, principles and methods in an area of learning. These essential concepts, principles and methods provide a frame of reference for organising and understanding specific facts and procedures. The development of deep understanding usually requires significant time and may occur only over multiple years of schooling. In general, deep understanding and thinking are not 'outcomes' that can be recorded as present or absent on a checklist; they are reflected in a learner's ability to transfer and apply their knowledge to a growing range of unseen and increasingly complex situations.

\section{Assessing and reporting}

If the curriculum is presented as an assembly line, with all students being delivered the same content at the same time and being given the same amount of time to master it, then the important question is how much of that content each student has learnt and can demonstrate. At the end of each year, students are assessed and graded on that year's content before moving to the next year's curriculum. The fundamental purpose is to determine how well students have learnt what has been taught. Assessments also may be undertaken during the year to identify individual gaps in learning, provide feedback, and identify material that may need to be retaught, but whenever assessment occurs, its core purpose under this model is to judge how well students have learnt a body of taught content. And these judgements typically are conveyed as marks, percentages or grades.

A consequence of this approach is that each new school year is treated as a fresh start, largely independent of the prior year. The intention is that the grade a student receives on the year's curriculum should be uninfluenced by the grade they received on the previous year's curriculum; years of school are independent stations on the assembly line. As a result, a student can receive the same grade every year. A student who receives a grade of, say $D$, year after year is given little sense of the absolute progress they are making and, worse, may be sent a message that there is something stable about their ability to learn (they are a D-student).

Again, in industrial (and agricultural) settings, it is common practice to grade the products or outcomes of production processes for their quality. The assessment and grading of student performance on each year-level curriculum mirrors this practice.

In contrast, research into learning reveals the importance of seeing learning as a continuous process through which learners build new learning on prior learning. Learning is less a process of mastering isolated outcomes on a checklist, and more an ongoing process of developing increasingly sophisticated knowledge, deeper understandings, and higher levels of skill over time. One of the most effective ways to promote learning is to establish the point a learner has reached in their progress and to provide well-targeted learning opportunities that build from that point. This is the realisation that underpinned Lev Vygotsky's Zone of Proximal Development ${ }^{2}$ and David Ausubel's observation more than half a century ago:

If I have to reduce all of educational psychology to just one principle, I would say this: the most important single factor influencing learning is what the learner already knows. Ascertain this and teach him accordingly (Ausubel, 1968, p. vi). ${ }^{3}$

Vygotsky, L. S. (1978). Mind in society. Harvard University Press

Ausubel, D. P. (1968). Educational psychology: A cognitive view. Holt, Rinehart and Winston Inc. 
Two implications follow from these research findings. First, all learning builds on prior learning and lays the foundations for potential future learning. Learning occurs when connections are built between new information and existing knowledge. For these reasons, learning is best conceptualised as a continuous process, and the sequencing of learning opportunities to build increasing depth is a key to successful teaching and learning. Second, to build from the point an individual has reached in their learning, it is necessary to 'ascertain' that point. Thus a focus on learning gives assessment a new purpose. No longer is the purpose to determine how well students have learnt what they have been taught; the new purpose is to establish where learners are in their long-term learning progress. At a fundamental level, the assessment purpose switches from judging to understanding.

In practice, the education process also sometimes includes selection points at which only some students are chosen for entry to the next education phase or course. At these times, the main purpose of assessment is not to inform learning, or even to grade performance, but to compare and select individuals. Because of the consequences for students, such assessments often distort teaching and learning. For example, if written examinations are a major component of the selection process, teaching and learning may overemphasise the recall of knowledge and theory and underemphasise the ability to apply knowledge, critical and creative thinking, and problem-solving. Selection processes need to be recognised as external influences that have more in common with assembly lines than human learning.

When the focus is on learning rather than grading or selecting, student progress (or growth) becomes a critical consideration. As already noted, this concept is largely absent from an education model that prioritises the achievement of individual outcomes, grades year-level performances, and includes high-stakes assessments for managing student flows. Learning, on the other hand, leads to student progress/growth in the form of increasingly sophisticated knowledge, deeper understandings, and higher levels of skill. To draw inferences about learning, it is necessary to evaluate progress toward higher levels of knowledge, understanding and skill.

Under a learning model, assessments are designed to establish the points individuals have reached in their learning (what they know, understand and can do at the time of assessment), conceptualised as positions on a continuum or progression of learning. These guide next steps in teaching and learning. Such assessments also can be used to monitor learning progress over time - essential information for evaluating the effectiveness of teaching strategies and interventions and if students are to see and appreciate the progress they are making and to develop positive views of themselves as learners.

In summary, current education structures and processes, including the organisation and delivery of the curriculum, and assessment and reporting arrangements, are largely 20th century inventions introduced as a response to mass education. This response includes grouping all students by age, delivering all students the same content for the same amount of time, grading performances on this common content, and then advancing students in unison to the next stage of the curriculum. Australian schooling has not always been organised in this way, and is highly unlikely to be organised in this way in the future. The alternative will recognise that, despite efforts to standardise learning, individuals remain at very different points in their learning, make progress at different rates, and have very different learning needs. The future organisation of schooling will be guided more by our emerging understandings of human learning than by education models of the past. 